\title{
The Hedgehog-binding proteins Gas1 and Cdo cooperate to positively regulate Shh signaling during mouse development
}

\author{
Benjamin L. Allen, ${ }^{1}$ Toyoaki Tenzen, ${ }^{2}$ and Andrew P. McMahon ${ }^{1,3}$ \\ ${ }^{1}$ Department of Molecular and Cellular Biology, Harvard University, Cambridge, Massachusetts 02138, USA; ${ }^{2}$ Center \\ for Regenerative Medicine, Massachusetts General Hospital, Boston, Massachusetts 02114, USA
}

\begin{abstract}
Hedgehog $(\mathrm{Hh})$ signaling is critical for patterning and growth during mammalian embryogenesis. Transcriptional profiling identified Growth-arrest-specific 1 (Gas1) as a general negative target of Shh signaling. Data presented here define Gas1 as a novel positive component of the Shh signaling cascade. Removal of Gas1 results in a Shh dose-dependent loss of cell identities in the ventral neural tube and facial and skeletal defects, also consistent with reduced Shh signaling. In contrast, ectopic Gas1 expression results in Shh-dependent cell-autonomous promotion of ventral cell identities. These properties mirror those of Cdo, an unrelated, cell surface Shh-binding protein. We show that Gas1 and Cdo cooperate to promote Shh signaling during neural tube patterning, craniofacial, and vertebral development. Overall, these data support a new paradigm in Shh signaling whereby positively acting ligand-binding components, which are initially expressed in responding tissues to promote signaling, are then down-regulated by active Hh signaling, thereby modulating responses to ligand input.
\end{abstract}

[Keywords: Mouse; Hedgehog; neural tube; development; Gas1; Cdo]

Supplemental material is available at http://www.genesdev.org.

Received February 20, 2007; revised version accepted April 3, 2007.

Nearly all developmental decisions during embryogenesis are regulated by a relatively small number of families of secreted growth factors and morphogens, including fibroblast growth factors (Bottcher and Niehrs 2005), Wnts (Logan and Nusse 2004), transforming growth factor- $\beta$ family members (Massague 1998), and Hedgehog (Hh) proteins (McMahon et al. 2003). Importantly, these secreted ligands often act on cells at a significant distance from their source (Ashe and Briscoe 2006), and, in the case of Wnts and $\mathrm{Hh}$, these ligands also undergo various lipid modifications that regulate both their range and level of activity (Miura and Treisman 2006). Understanding how the trafficking, turnover, and signaling levels of these factors are regulated in the extracellular matrix and at the cell surface are critical for a complete mechanistic understanding of their actions.

$\mathrm{Hh}$ proteins in the mouse are initially generated as $45-\mathrm{kDa}$ precursor proteins that subsequently undergo autocatalytic cleavage and concomitant cholesterol modification and palmitoylation. The resulting $\mathrm{N}$-terminal $19 \mathrm{kDa}$, dually lipidated, secreted molecule is responsible for all known $\mathrm{Hh}$ signaling activity (Ingham and McMahon 2001). Of the three mammalian Hh family

${ }^{3}$ Corresponding author.

E-MAIL mcmahon@mcb.harvard.edu; FAX (617) 496-3763.

Article is online at http://www.genesdev.org/cgi/doi/10.1101/gad.1543607. members (Indian, Desert, and Sonic), Sonic Hedgehog (Shh) has been the most widely studied, in large part because of its role as a morphogen in two key developmental events-the regulation of digit number and polarity, and the specification of ventral cell identities in the developing CNS (for review, see McMahon et al. 2003).

In the developing neural tube, Shh is initially expressed in the notochord underlying the ventral neural tube; as development progresses, Shh autoinduces a secondary domain of Shh production within the floor plate (FP) of the neural tube at the ventral midline (Echelard et al. 1993). Several lines of evidence indicate that Shh acts in a concentration-dependent manner to specify all ventral cell types of the developing neural tube (for review, see Jessell 2000; Briscoe and Ericson 2001; McMahon et al. 2003). Specifically, Shh represses (Class I genes; e.g., Pax6, Pax7) or induces (Class II genes; e.g., Nkx2.2, Olig2) the expression of several transcription factors at distinct concentration thresholds. Subsequent cross-repressive interactions between these regulatory factors sharpen the boundaries between different progenitor domains within the ventral neural tube (Briscoe et al. 2000). Importantly, even relatively small (approximately twofold) changes in Shh concentration result in the specification of distinct cell types (Ericson et al. 1997).

Such strict requirements for the level of Shh protein 
raises the question of how the levels and activity of Shh ligand are regulated such that each ventral cell type is specified at the correct position and in the appropriate numbers within the developing neural tube. One answer lies in mechanisms that exist at the cell surface to regulate the distribution of Shh. Pioneering studies in Drosophila demonstrated that Patched (Ptc), the Hh receptor, acts not only to transduce a Hh signal, but is also a target of Hh signaling that acts as a negative feedback regulator. The up-regulation of Ptc in response to a $\mathrm{Hh}$ signal sequesters ligand, limiting its spread in responding tissues and modifying the response at a given position in the target field (Chen and Struhl 1996). In vertebrates, both Patched1 (Ptch1) (Goodrich et al. 1997) and Hedgehog-interacting protein-1 (Hhip1), which encodes a vertebrate-specific Shh-binding protein /Chuang and McMahon 1999), are up-regulated in response to Shh signaling. Their combined actvities restrict the distribution of Shh ligand during neural tube patterning, ensuring the correct specification of all ventral cell identities in their appropriate position (Jeong and McMahon 2005). In opposition to the above-mentioned negative feedback mechanisms, recent work has identified two additional Shh-binding cell surface proteins, Cdo and Boc, as negative targets of Shh signaling that function to positively regulate Shh signaling (Okada et al. 2006; Tenzen et al. 2006; Yao et al. 2006; Zhang et al. 2006).

One hypothesis that emerges from these reports is that the levels of Shh protein at the cell surface are controlled by transcriptional up-regulation of negative feedback components such as Ptchl and Hipl, and concomitant down-regulation of positively acting Shh-binding proteins such as Cdo and Boc. While previous mutational analyses have established the importance of Ptch1 and Hip1 in the general negative regulation of Hh signaling (Goodrich et al. 1997; Chuang and McMahon 1999; Milenkovic et al. 1999; Chuang et al. 2003; Jeong and McMahon 2005), genetic analysis of Cdo and Boc have revealed only limited, tissue-specific roles for these structurally related proteins in the promotion of Shh signaling (Cole and Krauss 2003; Okada et al. 2006; Tenzen et al. 2006; Zhang et al. 2006). Although it is possible that semiredundant functions of $\mathrm{Cdo}$ and Boc are responsible for the relatively mild effects on Shh signaling, another possibility is that other, unidentified components compensate for their loss of function. Interestingly, transcriptional profiling experiments identified Growth-arrest-specific 1 (Gas1) as a gene commonly down-regulated in response to Shh signaling in multiple tissues, a transcriptional signature shared with $C d o$ and $B O C$ ( T. Tenzen and A.P. McMahon, in prep.).

Gas1 encodes a 45-kDa GPI-anchored cell surface protein that binds Shh with high affinity $\left(\mathrm{K}_{\mathrm{d}} \sim 6 \mathrm{nM}\right)$ (C.S. Lee et al. 2001a). Gas1 was initially described as an antagonist of Shh signaling, based on ectopic expression studies in the developing somite (C.S. Lee et al. 2001a) and tooth (Cobourne et al. 2004). Paradoxically, the phenotypes reported for Gas1 mutant mice reveal eye (C.S. Lee et al. 2001b), cerebellar (Liu et al. 2001), and limb deficiencies (Liu et al. 2002) that are more consistent with reduced Shh signaling (Wang et al. 2002; Harfe et al. 2004; Lewis et al. 2004).

To address whether Gas1 functions to promote or antagonize Shh signaling, we examined the role of Gas1 in the Shh-mediated specification of ventral cell types and other Shh-dependent patterning events. This study establishes that Gas1 functions in vivo to promote Shh signaling during embryogenesis. Additionally, we demonstrate overlapping roles for Gas1 and Cdo in the positive regulation of an appropriate transcriptional response to Shh signaling in Shh target fields. Overall, these findings suggest a new paradigm of Shh signaling where the negative transcriptional regulation of positively acting, cooperative Shh-binding components constitutes part of the dynamic response to a Shh morphogen.

\section{Results}

Gasl is a negative target of Shh signaling that is initially expressed in Shh-responsive tissues

Multiple transcriptional profiling analyses were performed at several stages of early mouse development (embryonic days 8.5-10.5 [E8.5-E10.5]) in distinct Shh target fields. These data, which will be presented in detail elsewhere (T. Tenzen and A.P. McMahon, in prep.), identified a number of genes with common, tissue-independent signatures of Shh signaling activity. Of those genes commonly repressed by Shh signaling, Gas1 stood out as a general negative target of Shh regulation, a result consistent with the original description of Gas1 expression (C.S. Lee et al. 2001a). To confirm that Gas1 is, in fact, a general negative target of Shh, in situ hybridization analysis of Gas1 expression was performed at E8.5 on wild-type, $\mathrm{Smo}^{-1-}$, and Ptch1 $1^{-/}$embryos (Fig. 1). Gas1, which is normally strongly expressed in surface ectoderm of the headfold region and somites (Fig. 1A), is up-regulated in $\mathrm{Hh}$ loss-of-function $\mathrm{Smo}^{-/-}$embryos (Fig. 1B), while its expression is almost completely abolished in Hh gain-of-function Ptch1 ${ }^{-/}$embryos (Fig. 1C), as expected for a general negative target of Shh signaling.

To more closely examine the expression of Gas1 in Shh-responsive tissues in conjunction with Shh-mediated patterning, we used a novel Gas $1^{\text {LacZ }}$ allele (Martinelli and Fan 2007) in which the entire coding region of Gas1 is replaced by a tau-LacZ fusion protein (Callahan and Thomas 1994). Whole-mount and section views of $\beta$-galactosidase activity (Fig. 1D-AA) reveal that Gas1 is present throughout the neural tube at E8.5, including low levels of notochord expression (arrows in Fig. 1F,J). Additionally, Gas1 expression correlates temporally with the Shh-dependent specification of ventral neural cell fates, as assayed by expression of Nkx6.1, a marker of the vp2, vpMN, and vp3 neural progenitor domains (Fig. 1K). One day later, in E9.5 embryos, Gas1 is restricted to more dorsal regions, although expression still overlaps the dorsal-most subset of Shh-responsive, Nkx6.1 ${ }^{+}$cells (Fig. 1L-S). At E10.5, Gas1 expression remains dorsally restricted, and includes an additional domain of expression in commissural axons that project 


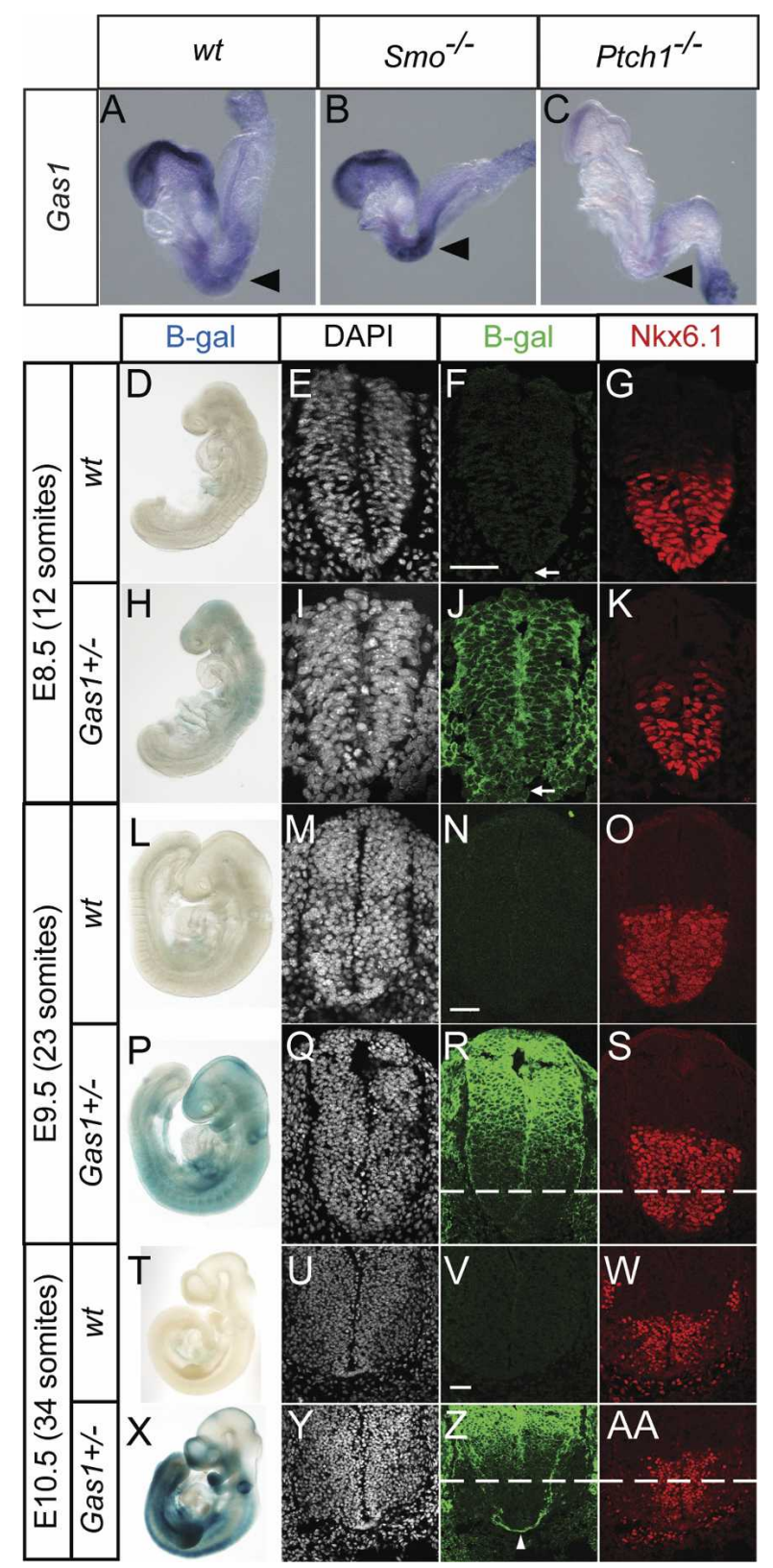

Figure 1. Gas1 is a general negative target of Hedgehog signaling that is expressed in the ventral CNS during early stages of neural tube patterning. Analysis of Gas1 expression in wildtype $(A), \mathrm{Smo}^{-/-}(B)$, and $P$ tch1 ${ }^{-/-}(C)$ eight- to 10 -somite mouse embryos. Black arrowheads highlight Gas1 expression in somites. Whole-mount LacZ stain of wild-type $(D, L, T)$ and $\operatorname{Gas1}^{+/-}(H, P, X)$ embryos at the indicated stages. Embryos were sectioned at the forelimb level (for E9.5 and E10.5) and stained with DAPI $(E, I, M, Q, U, Y)$, anti- $\beta$-gal $(F, J, N, R, V, Z)$, and antiNkx6.1 $(G, K, O, S, W, A A)$. Dashed lines in $R, S, Z$ and $A A$ denote the ventral limit of Gas1 expression in adjacent sections following antibody staining for $\beta$-galactosidase. Arrows in $F$ and $J$ denote notochord. Arrowhead in $Z$ indicates Gas1-expressing commissural axons. Bars: $F, N, V, 50 \mu \mathrm{m}$.

ventrally from the dorsal neural tube to cross the FP (Fig. $1 Z$, arrowhead) via a Shh-dependent guidance process (Charron et al. 2003; Okada et al. 2006). These results demonstrate that in the neural tube Gas1 is initially present in all Shh-responsive cells at the outset of Shh signaling, but gradually becomes more dorsally restricted, as the levels of Shh increase and the Shh signaling domain expands, consistent with Gas1 being a negative target of Shh regulation.

\section{Craniofacial and skeletal defects in Gas1/-- and $\mathrm{Gas}^{-1-}$; $\mathrm{Shh}^{+/-}$embryos}

To address the potential involvement of Gas1 in Shh signaling, Gas1-1- embryos were analyzed. At E18.5, Gas1 mutants are easily identified by their small eyes (micropthalmia) (C.S. Lee et al. 2001b) and generally reduced body size. Skeletal analysis of the heads of $\mathrm{Gas1}^{-/-}$ E18.5 embryos indicates several defects consistent with reduced Hh signaling (Jeong et al. 2004), including a truncated maxilla, reduced parietal bone, and disrupted tympanic bone (Fig. 2A-C).

If the skeletal defects observed in $\mathrm{Gas}^{-/-}$embryos reflect reduced levels of Shh signaling, then lowering the dosage of $S h h$ would be expected to enhance these phenotypes. To test this prediction, Gas1; Shh compound mutants were analyzed. While $\mathrm{Gas1}^{+-}$; $\mathrm{Shh}^{+-}$embryos

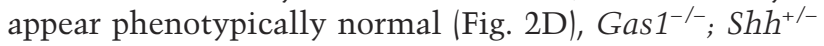
embryos are severely reduced in overall body size (data not shown) and display pronounced skeletal defects (Fig. $2 \mathrm{E})$ that are significantly more severe than those seen in

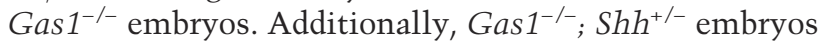
display other defects not seen in $\mathrm{Gas1}^{-/}$embryos, the most obvious of which are a profound truncation of the mandible (Fig. 2E) and axial skeletal deficiencies that include severely reduced ossification centers in vertebral bodies, and partial fusion of the intervertebral discs (data not shown). These phenotypes are reminiscent of mice that lack the Hh-specific transcriptional effector Gli2 (Mo et al. 1997).

Examination of the limbs of $\mathrm{Gas1}^{-/-}$embryos also reveals an apparent reduction in Shh signaling, a phenotype first observed by Martinelli and Fan (2007). In the limb, digit 1 is Shh-independent, while all other digits are Shh-dependent (Chiang et al. 2001; Lewis et al. 2001). Of these, only digit 2 is completely dependent on secreted Shh; digit 3 is a mosaic of cells, a subset of which originate from Shh-expressing cells, while digits 4 and 5 are wholly derived from Shh-producing cells (Harfe et al. 2004). Importantly, Gas1 is expressed in the anterior two-thirds of the developing limb bud mesenchyme starting at E9.0 (Liu et al. 2002). In $\mathrm{Gas1}^{-/}$embryos, forelimb digits 2 and 3 are fused, while digit 2 or 3 is completely absent from the hindlimbs of $\mathrm{Gas1}^{-/} \mathrm{em}-$ bryos (Supplementary Fig. 1). Reduction of Shh dosage in $\mathrm{Gas1}^{-/-}$; Shh ${ }^{+-}$embryos enhances the forelimb defect such that now one digit ( 2 or 3 ) is completely absent. In contrast to the digits, the long bones of E18.5 $\mathrm{Gas1}^{-/-}$ embryos are overtly normal (data not shown), suggesting that there is not a significant effect on Ihh-dependent long bone growth in Gas1 mutants at this stage.

Given the severe craniofacial defects observed at

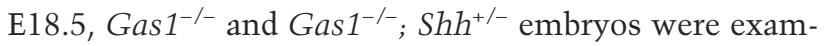




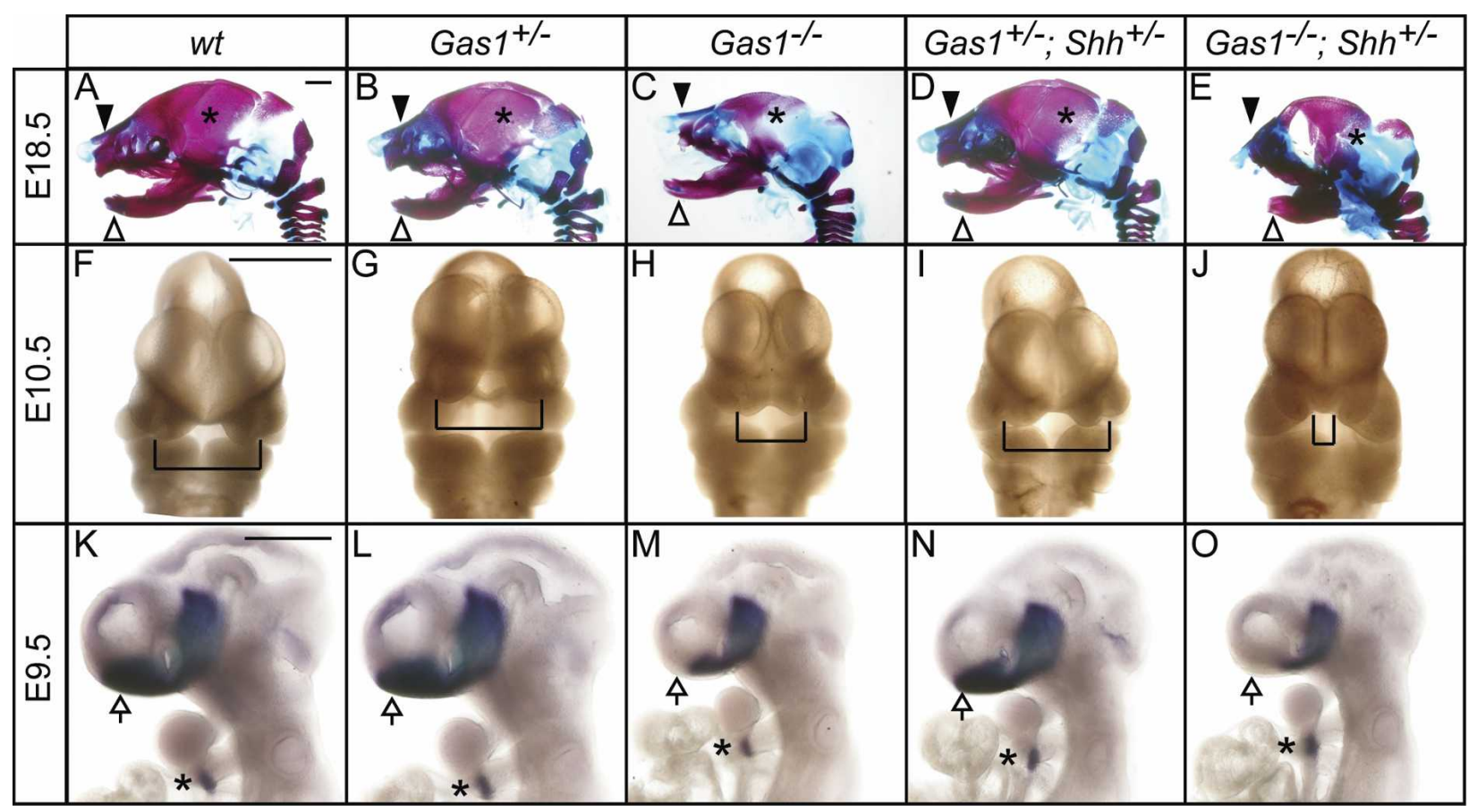

Figure 2. Genetic interactions between Gas1 and Shh result in craniofacial defects and abnormal forebrain patterning. Lateral view of E18.5 embryonic heads $(A-E)$ following Alcian Blue (cartilage) and Alizarin Red (bone) skeletal staining. Black arrowheads denote maxillary processes; white arrowheads indicate mandibular components. Asterisks in $A-E$ identify the parietal bone. (F-J) Frontal view of E10.5 embryonic heads. Brackets highlight the medial nasal processes. (K-O) In situ hybridization detection of $N k x 2.1$ expression in E9.5 embryonic forebrain. Arrows point to forebrain, while asterisks in $K-O$ designate thyroid gland. Bars: $A, F, K, 50 \mu m$.

ined at earlier developmental time points to determine when these defects first manifest themselves. At E10.5 Gas $1^{-1-}$ embryos display partial fusion of the medial nasal processes (Fig. 2F-H), a phenotype similar to that of Cdo ${ }^{-/-}$embryos (Tenzen et al. 2006; Zhang et al. 2006). Consistent with the increased severity of the facial phenotypes at E18.5, this phenotype is enhanced in $\mathrm{Gas}^{-/-}$; $\mathrm{Shh}^{+/-}$compound mutants, leading to a complete fusion of the medial nasal processes (Fig. 2I,J). Interestingly, a similar genetic interaction is observed between $C d o$ and Shh (Tenzen et al. 2006). These early facial phenotypes likely represent a secondary outcome stemming from an initial failure of Shh patterning of the rostral forebrain (Jeong et al. 2004). The reduced expression of the Shhdependent transcriptional regulator Nkx2.1 (Pabst et al. 2000) in the ventral telencephalon of Gas1 ${ }^{-/-}$embryos (Fig. 2K-M) and the further diminished expression in Gas1 $^{-/-}$; Shh ${ }^{+/-}$embryos (Fig. 2N,O) supports this view.

Loss of Gas1 results in a Shh dosage-dependent loss of ventral cell identities in the ventral neural tube

Shh signaling during development is best understood with respect to its role in patterning of the ventral neural tube. To explore the effects of Gas1 on Shh-dependent neural tube patterning we initially examined presumptive spinal cord regions at the forelimb level in E10.5 embryos. At the ventral midline, specification of FP cells requires the highest level of Shh signaling (Roelink et al.
1995) for the localized expression of FoxA2, itself a direct transcriptional regulator of Shh (Epstein et al. 1999; Jeong and Epstein 2003). When FoxA2 is first activated at the ventral midline, its expression overlaps with Nkx2.2, a determinant of ventrolateral vp3 interneuron progenitors (Jeong and McMahon 2005). Elevated FoxA2 levels and loss of Nkx2.2 within FP progenitors correlates with cells assuming a typical polarized FP morphology and transcriptional activation of Shh. Thus, FP induction is a dynamic process wherein a mature FP identity is $\mathrm{Nkx2.2^{- }}$, FoxA2 $2^{+}, \mathrm{Shh}^{+}$. Initial examination showed that FoxA2 is present in Gas1 $^{-/-}$embryos (Fig. 3A,C,E). Analysis of FoxA2 and Nkx2.2, however, revealed that their expression is almost completely overlapping at a time when $\mathrm{Nkx} 2.2$ is normally ventrolaterally restricted (Fig. 3K-S), suggesting that FP specification is incomplete. Quantitation of FoxA2 ${ }^{+}, \mathrm{Nkx} 2.2^{+}$cell number revealed a highly significant difference in the number of double-positive cells between wild-type and $\mathrm{Gas}^{-/-} \mathrm{em}$ bryos (Fig. 3T). Consistent with this view, Shh is also variably reduced or entirely absent from midline cells (Fig. 3, cf. F and B,D) of $\mathrm{Gas}^{-/-}$embryos. In addition, while reduction of Shh dosage has no effect on FoxA2 expression in $\mathrm{Gas1}^{+/-}$; Shh ${ }^{+/-}$embryos (Fig. 3G), Gas1-/-; $\mathrm{Shh}^{+/-}$embryos exhibit a complete loss of FoxA2 $2^{+}$cells (Fig. 3I). Importantly, Shh expression at the midline is also lost in all Gas1 $^{-1-}$; Shh ${ }^{+/-}$embryos (Fig. 3H,J). Thus, FP specification is dependent on Gasl action in a Shh dosage-dependent manner. 


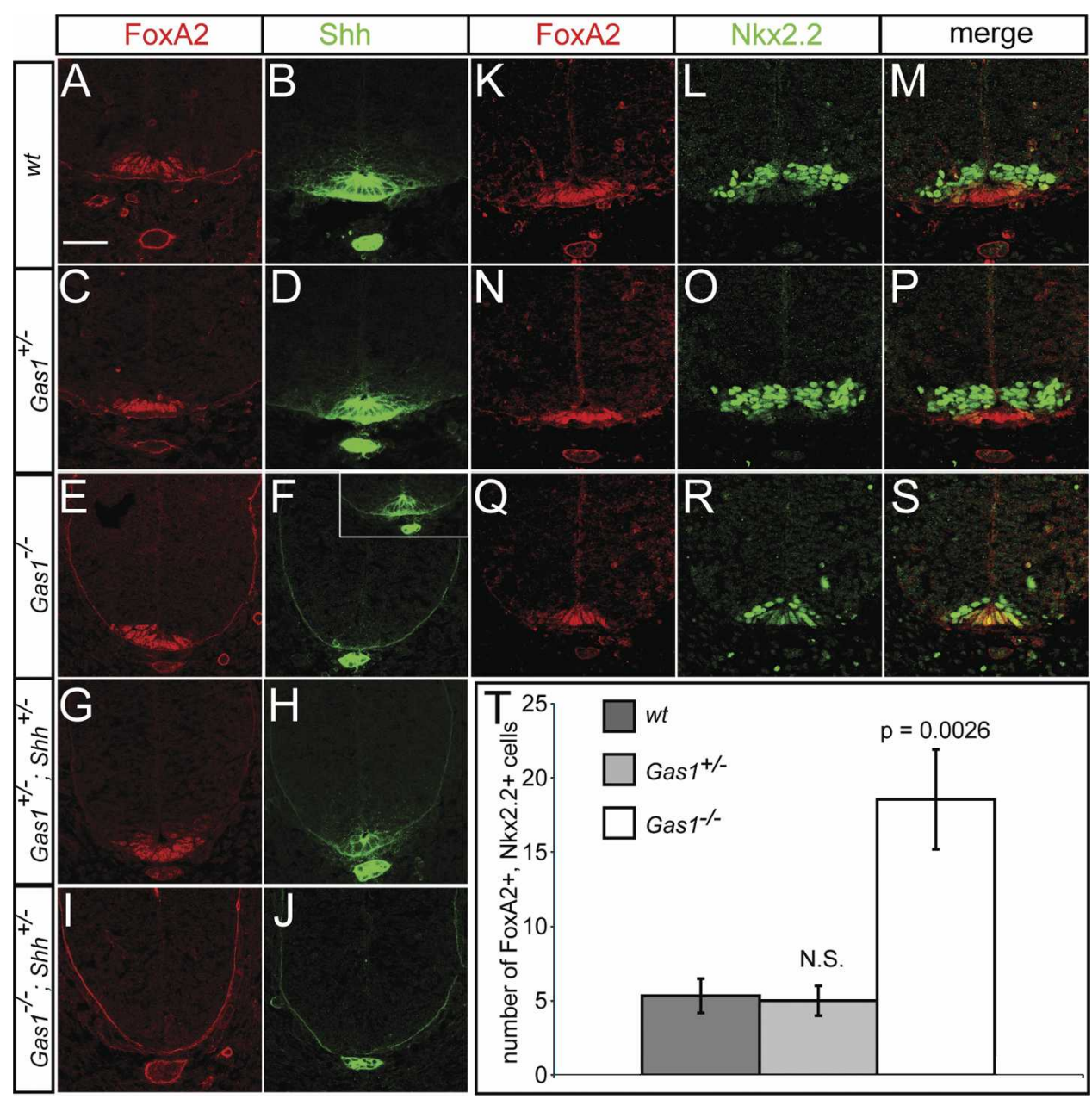

Figure 3. Compromised FP specification in Gas1 $1^{-/-}$embryos is exacerbated by reducing Shh dosage. Antibody detection of FoxA2 (red; $A, C, E, G, I$ ) and Shh (green; $B, D, F, H, J)$ in forelimb-level sections of E10.5 Gas1; Shh embryos. Inset in $F$ denotes variable FP expression

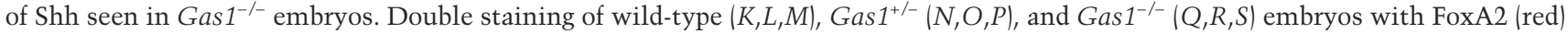
and Nkx2.2 (green). (T) Quantitation of FoxA2, Nkx2.2 double-positive cells. Error bars represent the mean \pm SD of three different

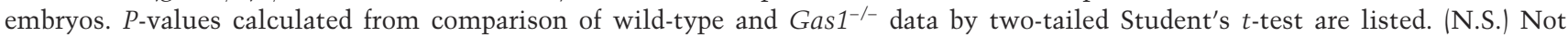
significant $(p>0.5)$. Bar: $A, 50 \mu \mathrm{m}$.

To explore more fully the role of Gas1 in ventral neural tube patterning, specification of $\mathrm{vp} 3\left(\mathrm{Nkx} 2.2^{+}\right)$interneuron progenitors and $\mathrm{pMN}\left(\mathrm{Olig} 2^{+}\right)$motorneuron progenitors was examined in $\mathrm{Gas1}^{1^{-/}}$and $\mathrm{Gas1}^{1^{--}}$; $\mathrm{Shh}^{+-}$ embryos (Fig. 4). Specification of vp3 progenitors requires a significantly higher level of Shh signal than pMN progenitors (Ericson et al. 1997), in agreement with the more dorsal position of the pMN progenitor pool. $\mathrm{Nkx} 2.2^{+} \mathrm{vp} 3$ progenitors are significantly reduced in Gas $^{-1-}$ embryos (Fig. 4A-L), and further reduced in Gas1 $^{-/}$; $\mathrm{Shh}^{+/-}$embryos (Fig. 4M-U). In contrast, while Olig2 ${ }^{+} \mathrm{pMN}$ progenitors are not significantly affected in Gas1 $1^{-/-}$embryos (Fig. 4K), they are dramatically reduced in $\mathrm{Gas1}^{-/-}$; Shh ${ }^{+-}$embryos (Fig. 4S, V), though their relative position dorsal to $\mathrm{Nkx} 2.2^{+}$progenitors is preserved (Fig. 4L,T). Surprisingly, Olig2 ${ }^{+}$cell numbers are increased in Gas1 ${ }^{+/-}$; Shh ${ }^{+/-}$embryos (Fig. 4O) compared with wild-type littermates (Fig. 4C), suggesting that both Gas1 and Shh levels are critical for proper specification of ventral cell identities. Overall, these data suggest that although cells may be exposed to reduced levels of Shh, or are less able to respond to Shh, the graded response to Shh appears to be maintained. Additionally, examination of other markers of neural progenitor cell specification that are positively (Isl1 $1^{+} \mathrm{pMN}, \mathrm{En} 1^{+} \mathrm{v} 1$, or Nkx6.1 $1^{+}$ vp2, pMN, vp3) or negatively (Pax6, Pax7) regulated also show modified expression consistent with reduced Shh signaling (Supplementary Fig. 2; data not shown). Importantly, despite the strong expression of Gas1 in dorsal domains, specification of general dorsal cell identities $\left(\mathrm{Pax6}^{+}, \mathrm{Pax}^{+}\right)$and specific $\mathrm{Msx}^{+}$roof plate (data not shown) and Math $1^{+}$dp1 progenitors (Supplementary Fig. 2) is normal in both $\mathrm{Gas1}^{-1-}$ and $\mathrm{Gas1}^{-/-}$; $\mathrm{Shh}^{+/-} \mathrm{em}-$ bryos. Overall, these results are consistent with Gas1 functioning to specifically modulate the level of Shh signal that cells are exposed to during neural tube patterning.

The reduction of vp3 progenitors in $\mathrm{Gas1}^{-/-}$; $\mathrm{Shh}^{+/-}$ 


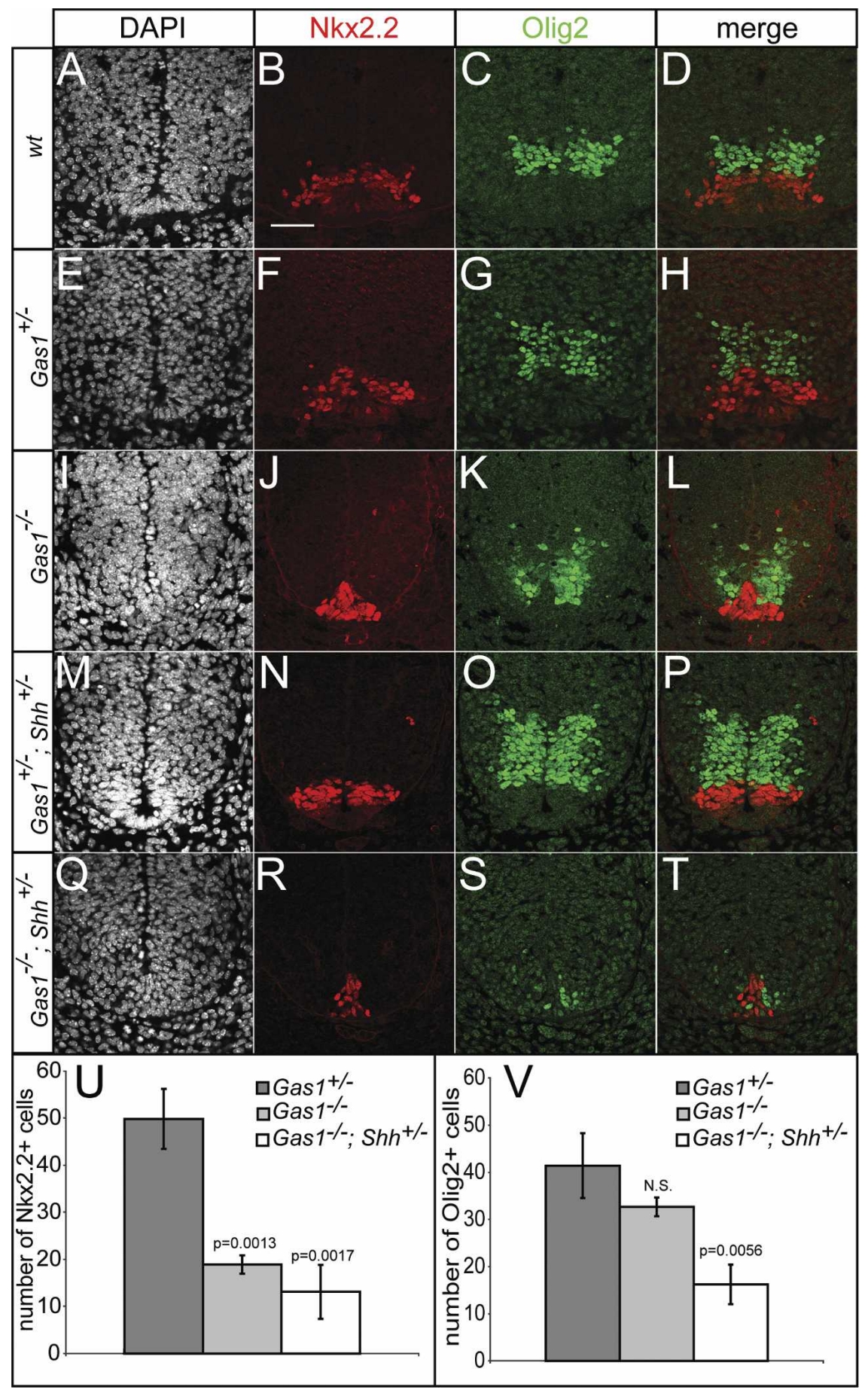

Figure 4. Reduced Olig2 ${ }^{+}$and $\mathrm{Nkx} 2.2^{+}$ cell specification in E10.5 Gas1; Shh compound mutants. DAPI $(A, E, I, M, Q)$, Nkx2.2 (red; $B, F, J, N, R)$, and Olig2 (green; $C, G, K, O, S)$ detection in forelimb-level E10.5 sections of Gas1; Shh embryos. $(D, H, L, P, T) \mathrm{Nkx} 2.2$ and Olig2 merged images are shown. Quantitation of numbers of $\mathrm{Nkx}^{2.2^{+}}(U)$ and Olig2 ${ }^{+}(V)$ cells in Gas1 $^{+/-}$(dark-gray bars), Gas1-/- (lightgray bars), and Gas1-/- Shh $^{+-}$(white bars) E10.5 embryos. Error bars represent the mean $\pm \mathrm{SD}$ of three different embryos. $P$ values calculated from comparison with $\mathrm{Gas1}^{+/-}$data by two-tailed Student's $t$-test are listed. (N.S.) Not significant $(p>0.1)$. Bar: $B, 50 \mu \mathrm{m}$. embryos is consistent with the phenotype of $\mathrm{Gli2}^{-/-}$ mice (Ding et al. 1998; Matise et al. 1998) that also fail to specify a Shh-expressing FP. However, Gas1-/-; Shh ${ }^{+-}$ embryos display an additional phenotype, a dramatic reduction in Olig2 ${ }^{+}$pMN progenitors at E10.5. To determine whether the loss of Olig2 ${ }^{+}$cells results from an initial failure in pMN specification, or in the later proliferation or maintenance of progenitors, we examined $\mathrm{Gas1}^{-/-}$; Shh ${ }^{+-}$embryos at E9.5 (Fig. 5). Examination of the FP marker FoxA2 in $\mathrm{Gas1}^{-/-}$and $\mathrm{Gas1}^{-/-}$; $\mathrm{Shh}^{+/}$em- bryos at E9.5 suggested that FP specification initiated relatively normally. However, only a few, weakly positive FoxA2 ${ }^{+}$cells were detected in $\mathrm{Gas1}^{-/}$; $\mathrm{Shh}^{+-}$embryos (Fig. 5A,D,G). Decreased Nkx2.2 expression was detected in Gas1-/- embryos (Fig. 5B,E); this phenotype was also enhanced by reducing Shh dosage in $\mathrm{Gas1}^{-/-}$; $\mathrm{Shh}^{+/-}$embryos (Fig. 5H). In contrast, Olig2 specification did not appear to be dramatically altered in $\mathrm{Gas1}^{-/-}$; $\mathrm{Shh}^{+/-}$embryos at E9.5 (Fig. 5C,F,I). Together these data suggest that Gas1 promotion of Shh signaling is required 
Figure 5. Reduced FoxA2 ${ }^{+}$and $\mathrm{Nkx} .2^{+}$, but not Olig2 ${ }^{+}$cell specification in E9.5 Gas1; Shh compound mutants. Forelimblevel sections of E9.5 wild-type $(A-C)$, Gas1 $^{-/-}(D-F)$, and Gas1 ${ }^{-/}$; Shh $^{+/-}(G-I)$ embryos were examined for FoxA2 (green; $A, D, G), \quad \mathrm{Nkx} 2.2(\mathrm{red} ; B, E, H)$, and Olig2 $(C, F, I)$ expression. Bar: $A, 50 \mu \mathrm{m}$.

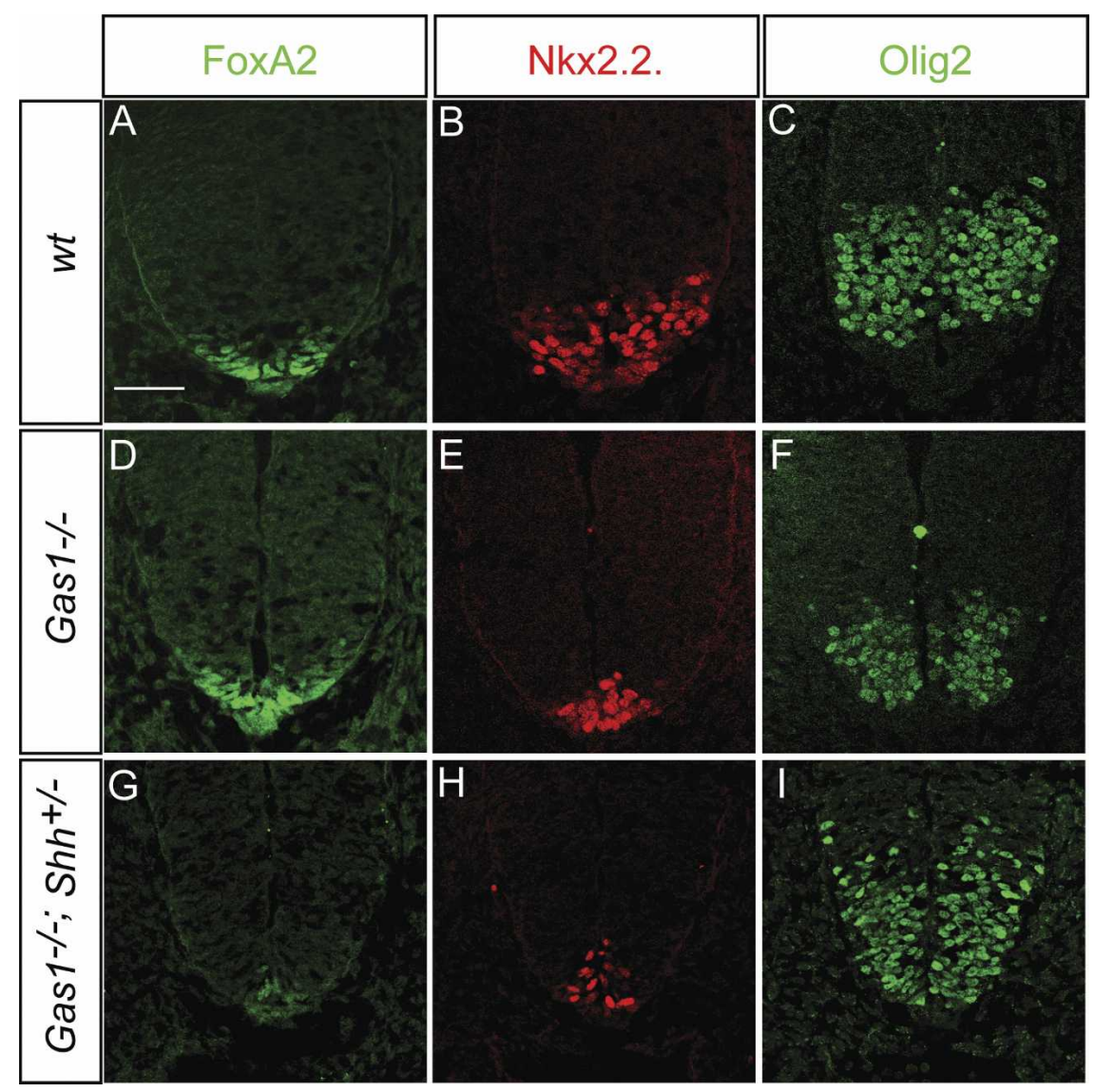

for initial specification of FP and vp3 cells functions while attenuation of Shh signaling in a Gas1-1- background argues for an ongoing Gas1-Shh dependence beyond initial specification for the proliferation or maintenance of ventral progenitor domains.

\section{Ectopic Gas1 expression in the chick neural tube results in Shh-dependent cell-autonomous promotion of ventral cell identities}

To directly test the ability of Gas1 to promote Shh signaling, a full-length Gas1 construct was electroporated into developing chick neural tubes (Fig. 6). In contrast to electroporation of a control vector (Fig. 6A-D), electroporation of Gas1 results in a significant cell-autonomous dorsal expansion of $\mathrm{Nkx} 6.1^{+}$and $\mathrm{Nkx} 2.2^{+}$progenitors (Fig. 6G-J; data not shown). Thus, Gas1 overexpression induces ectopic, Shh-dependent cell fates in the developing neural tube. Further, examination of $\mathrm{Nkx} 2.2$ and Olig2 in the same section revealed cell-autonomous dorsal expansion of both cell types in Gas1 electroporated neural progenitors (Fig. 6C,D,I,J). Importantly, the positions of ectopic Nkx2.2 $2^{+}$and Olig2 ${ }^{+}$cell identities relative to a ventral Shh signaling source are maintained (arrows in Fig. 6I,J). These data suggest that a graded response to Shh is still maintained, even in ectopic positions, when cells overexpress Gas1. Ectopic FoxA2 (Fig. 6 , cf. K,L and E,F) in Gas1 electroporated cells confirms that Gas1 is able to promote the Shh-dependent expansion of even the most ventral cell identities.

In addition to the dorsal expansion of Class II genes (e.g., Nkx2.2, Nkx6.1) that are normally activated in response to Shh signaling, Class I targets (e.g., Pax6, Pax7) normally repressed at distinct Shh thresholds (Briscoe et al. 2000) are also repressed at relatively more dorsal positions in cells ectopically expressing Gas1 (Fig. 6M-T). The cell-autonomous repression of Pax6 (Fig. 6Q,R) and Pax7 (Fig. 6S,T) at the dorsal-ventral intersect, the dorsal limit of Shh signaling (Wijgerde et al. 2002), but not at significantly more dorsal positions, confirms the Shhdependent specificity of Gas1 action. Finally, similar to the effects of overexpression of the cell surface, Shhbinding proteins Cdo and Boc (Tenzen et al. 2006), noncell-autonomous ventral expansion of Pax7 (Fig. 6S,T, arrowhead) is also detected when a significant population of Gas1 electroporated cells are positioned just ventral to the normal Pax7 domain, a result consistent with Gas1 sequestration of Shh ligand.

The promotion of Shh-dependent cell fates in the chick neural tube following ectopic Gas1 expression, taken together with the high-affinity interaction between these two proteins (C.S. Lee et al. 2001a), strongly suggests that Gas1 functions at the level of Shh ligand to promote Shh signaling. To directly test this idea, coelectroporation experiments were performed with Gas1 and Ptch1 $1^{\Delta l o o p 2}$, a variant of Ptch1 that lacks Shh binding, 


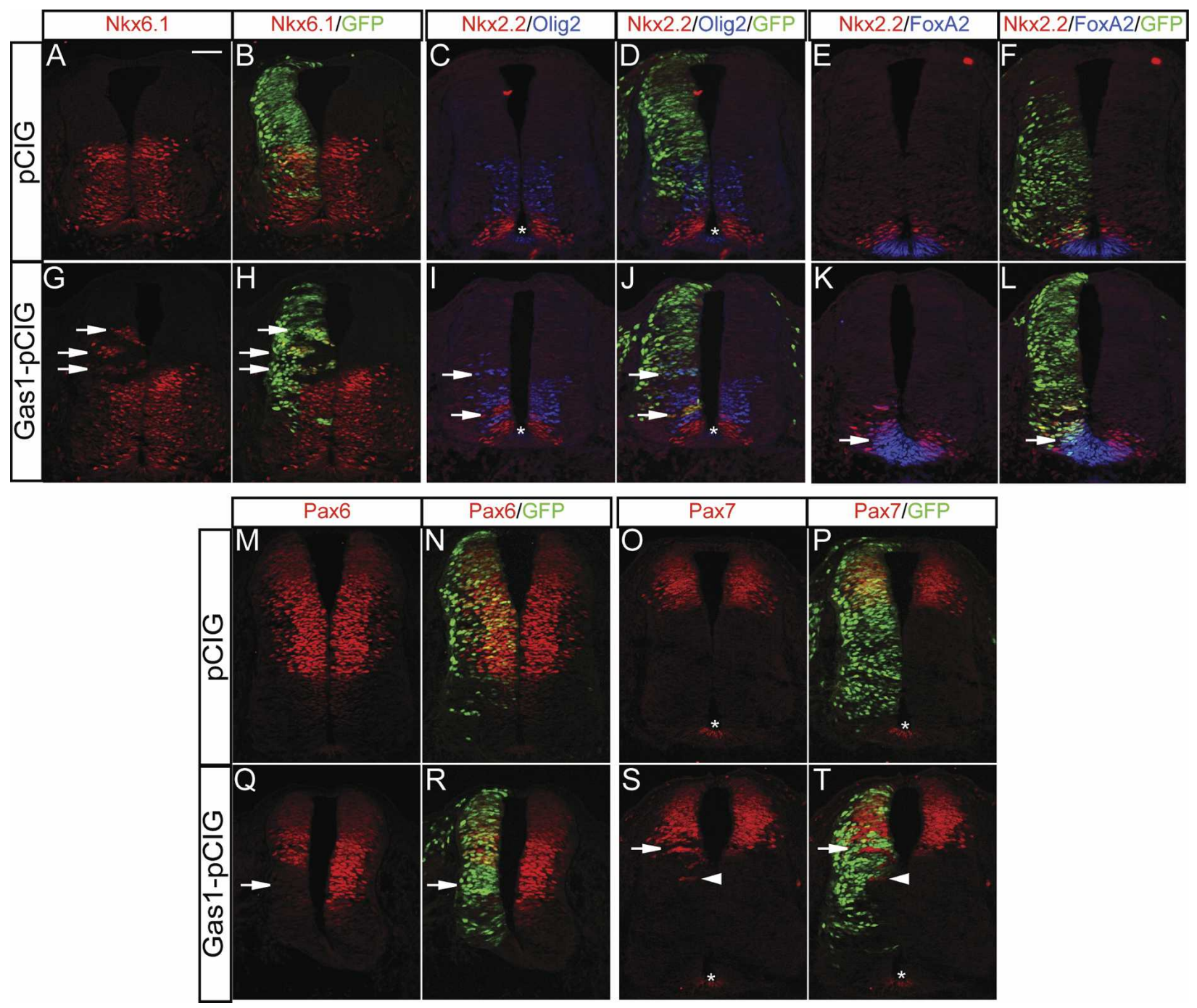

Figure 6. Ectopic expression of Gas1 promotes Shh-dependent cell fate specification in the developing chick neural tube. HH stage 19-22 chick neural tubes electroporated with pCIG $(A-F, M-P)$ or Gas1-pCIG $(G-L, Q-T)$ were sectioned at the forelimb level and stained with antibodies raised against Nkx6.1 (red; $A, B, G, H), \mathrm{Nkx} .2$ and Olig2 (red and blue, respectively; $C, D, I, J), \mathrm{Nkx} 2.2$ and FoxA2 (red and blue, respectively; $E, F, K, L)$, Pax $6(M, N, Q, R)$, and $\operatorname{Pax} 7(O, P, S, T)$. Arrows in $G, H, I, J, K$, and $L$ indicate ectopic expression of the indicated markers, while arrows in $Q, R, S$, and $T$ denote repressed marker expression. Arrowheads in $S$ and $T$ identify non-cellautonomous ventral expansion of Pax7 expression. Asterisks indicate nonspecific antibody background present in the FP of some sections. The results are representative of nine pCIG-electroporated embryos and 15 Gas1-pCIG electroporated embryos. Bar: A, $50 \mu \mathrm{m}$.

but retains the ability to inhibit Smo (Briscoe et al. 2001; Tenzen et al. 2006). If Gas1 functions at the level of ligand, then its effects on Shh-mediated patterning should be blocked by coexpression with Ptch1 ${ }^{\Delta l o o p} 2$. As expected, coelectroporation of Gas1 and a control vector resulted in the cell-autonomous promotion of Class II genes (e.g., Nkx6.1) (Fig. 7A-D), the cell-autonomous inhibition of Class I genes at the ventral limit of their normal expression domains (e.g., $P a x 7, P a x 6$ ) (arrows in Fig. 7I-L,Q-T), and the non-cell-autonomous expansion of Class I genes due to ligand sequestration (arrowheads in Fig. 7I-L,Q-T). In contrast, when coelectroporated with Gas1, Ptch1 $1^{\text {Lloop2 }}$ blocked both induction of Class II genes (Fig. 7E-H) and repression of Class I genes (ar- rows in Fig. 7M-P,U-X). Further, we observed a cell-autonomous expansion of Class I genes to more ventral positions (arrowheads in Fig. 7M-P,U-X) consistent with the reduced Shh signaling that results from Ptch $1^{\Delta \text { loop2 }}$ expression. These data support a model where Gas1 promotes Shh-dependent cell fates through a Shh ligandbinding-based mechanism (see Discussion).

\section{Gas1 and Cdo cooperate to promote Shh signaling}

Gas1 promotion of Shh signaling in target cells in a Shh dosage-dependent manner is similar to recent findings on the roles of the structurally unrelated, Shh-binding membrane proteins Cdo and Boc (Tenzen et al. 2006). 
Figure 7. Coexpression of Gas1 and Ptch1 ${ }^{\Delta l o o p 2}$ blocks the Gas1-mediated promotion of Shh-dependent cell fates. HH stage 21-22 chick neural tubes electroporated with Gas1-pCIG and pCIR $(A-D, I-$ $L, Q-T)$ or Gas1-pCIG and Ptch1 $1^{\Delta \text { loop2 }}$ pCIR $(E-H, M-P, U-X)$. Forelimb-level sections were examined for Nkx6.1 (blue. $C, G$ ), Pax7 (blue; $K, O)$, and Pax6 $(S, W)$ expression. Gas1-expressing cells are visualized with GFP (green), while pCIR and Ptch $1^{\Delta \text { loop2 }}$-pCIR-expressing cells are visualized with anti-DsRed antibodies (red). Arrows in $A-D$ indicate Gas1/pCIR-expressing cells that ectopically express Nkx6.1. Arrows in $E-H$ indicate similarly positioned cells that coexpress Gas1/ Ptch $1^{\Delta \text { loop2 }}$ that do not express Nkx6.1. Arrows in $I-L$ and $Q-T$ denote Gas1/pCIRexpressing cells that down-regulate Pax 7 and Pax6 expression, respectively; arrowheads indicate non-cell-autonomous expansion of Pax7 and Pax6. $(M-P, U-X)$ Cells that coexpress Gas/Ptch1 ${ }^{\Delta 10 o p 2}$ do not inhibit Pax7 and Pax6 expression (arrows). Cell-autonomous expansion of Pax7 and Pax6 is marked by arrowheads in $M-P$ and $U-X$. The results are representative of six Gas1/pCIR-electroporated embryos and eight Gas1/Ptch1 ${ }^{\Delta l o o p 2}$ embryos. Bar: $A$, $50 \mu \mathrm{m}$.

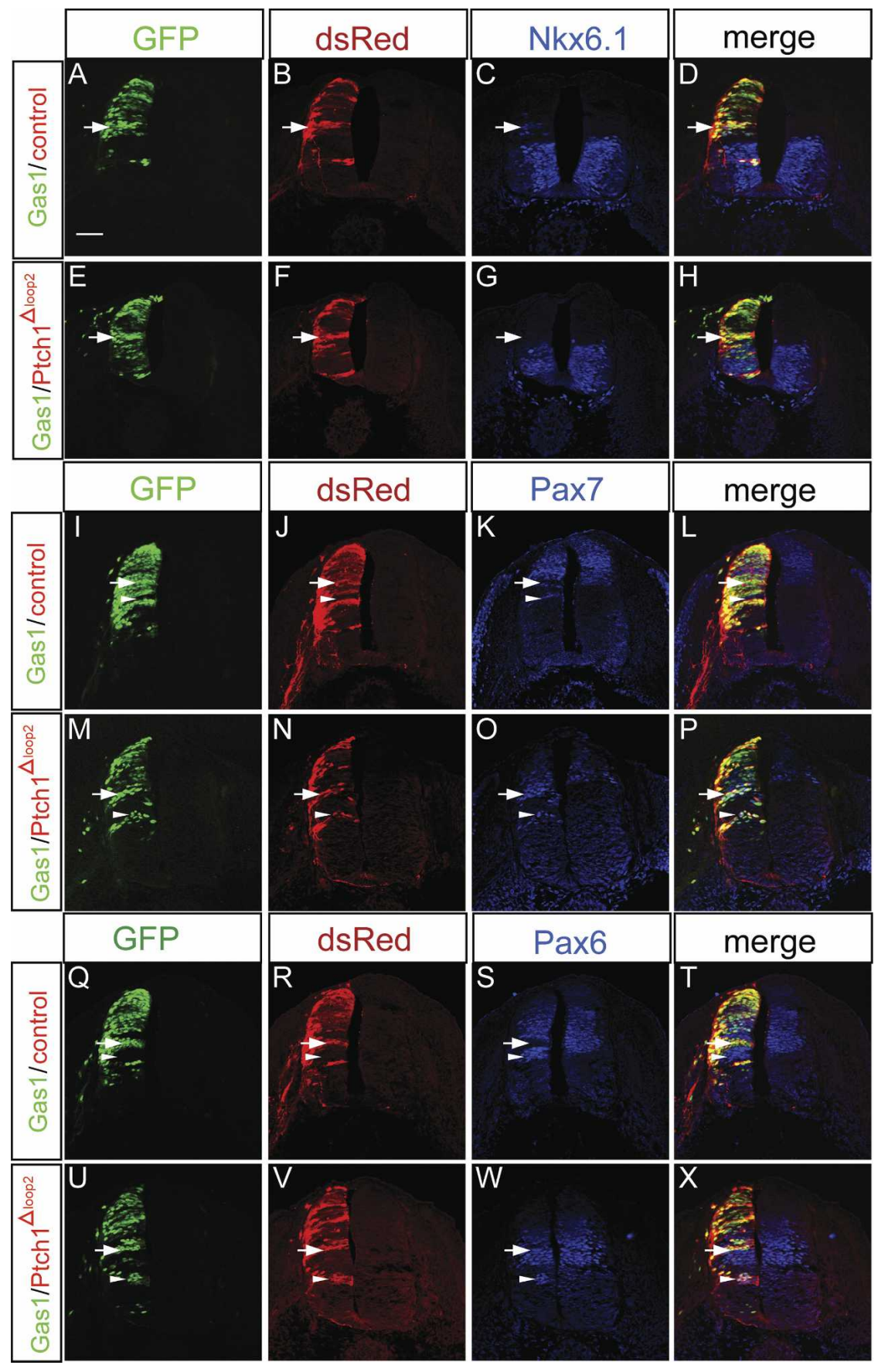

Additionally, a recent study has identified Boc as a receptor for Shh in commissural axon guidance /Okada et al. 2006). Given that Gas1 is also expressed in commissural axons (Fig. 1Z), we examined Gas1 mutants for a possible role in axon guidance. While Gas1-expressing axons project normally at E11.5 in Gas1 $1^{+-}$embryos (Supplementary Fig. 3B,E), aberrant axonal projections, visualized with anti- $\beta$-galactosidase antibody, are apparent in Gas1 ${ }^{-/-}$embryos that are misrouted through the Isl1 $/ 2^{+}$motor column (Supplementary Fig. 3A-H). It is difficult at present to determine whether these projection defects are due directly to a loss of a Gas1-Shh-based mechanism of axon guidance or are secondary to deficiencies in the specification of ventral populations-for example, the FP-that are known to have Shh-independent actions on commissural axon guidance.

Together, the above data raise the question of whether Gas1, Cdo, and Boc might cooperate to augment Shh signaling. To address this issue, $\mathrm{Gas1}^{+-} ; \mathrm{Cdo}^{+/-}$mice were generated and crossed to obtain $\mathrm{Gas1}^{-/-}$; $\mathrm{Cdo}^{-/-}$ double mutants (Fig. 8). Remarkably, an initial examination of facial development revealed a progressive increase in the severity of nasal process fusion as Gas 1 and Cdo activity are removed (Fig. 8A-G), such that $\mathrm{Gas1}^{-/-}$; 


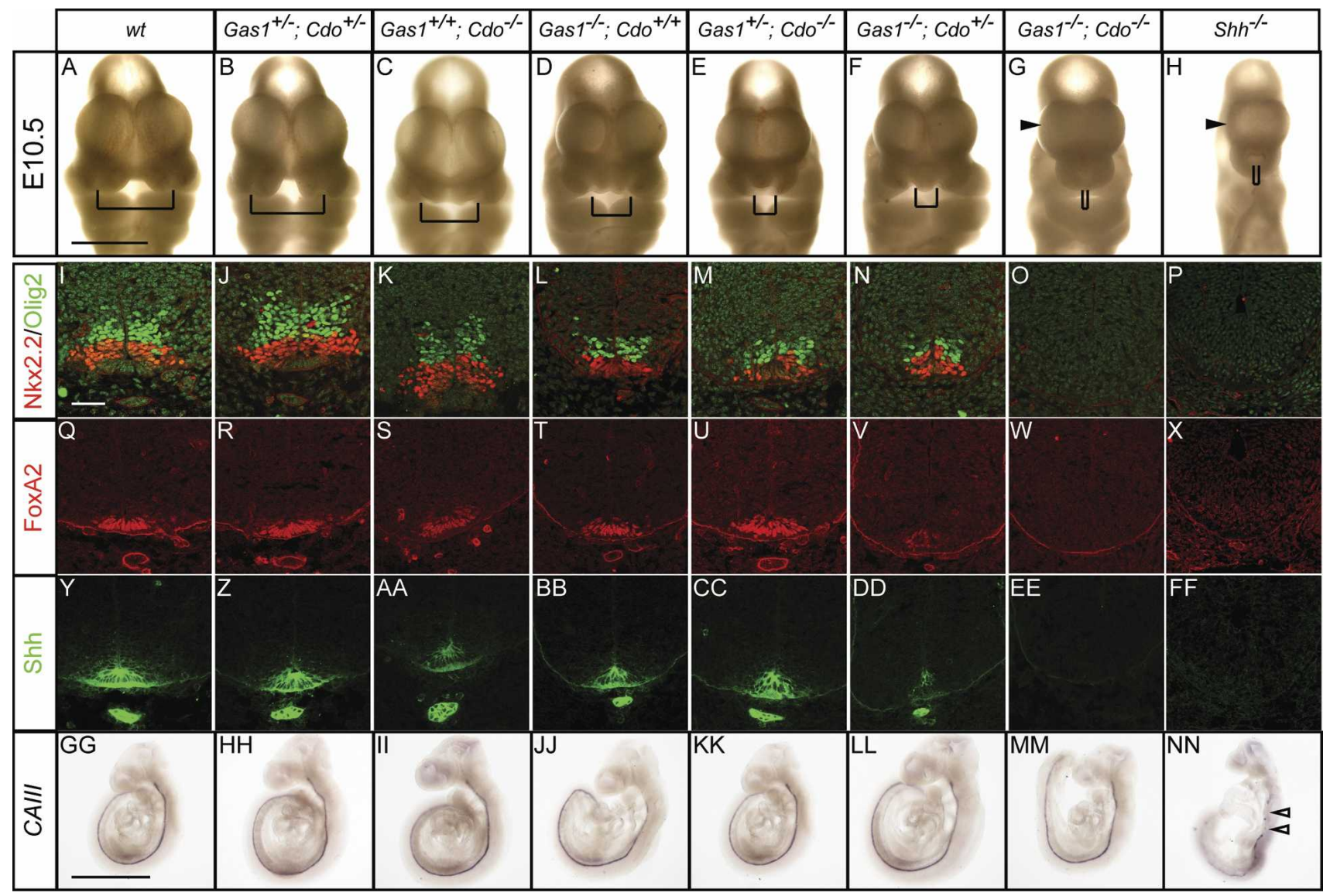

Figure 8. Gas1; Cdo compound mutants display severely reduced Shh signaling. $(A-G)$ Nasal process defects in E10.5 Gas1; Cdo embryos are shown. Brackets indicate the distance between nasal pits. $(H)$ A Shh ${ }^{-/-}$E10.5 embryo is shown for comparison. Examination of Nkx2.2 (red) and Olig2 (green) expression in E10.5 Gas1; Cdo (I-O) and $S_{h h^{-/}}(P)$ forelimb-level sections. Forelimb-level expression of FoxA2 (red; $Q-X)$ and Shh (green; Y-Z,AA-FF) in E10.5 Gas1; Cdo and Shh ${ }^{-/-}$embryos. In situ hybridization analysis of the notochord marker CAIII in E9.5 Gas1; Cdo embryos (GG-MM). Discontinuous CAIII expression is detected in a Shh ${ }^{-/-}$E9.5 embryo $(N N)$, indicative of notochord degeneration. Arrows in $N N$ highlight the broken CAIII expression. Bars: $A, 1 \mathrm{~mm} ; I, 50 \mu \mathrm{m}$; GG, $1 \mathrm{~mm}$. For $\mathrm{Gas1}^{-/-}$; $\mathrm{Cdo}^{-/-}$embryos, a total of five embryos were examined with similar results.

$\mathrm{Cdo}^{-/-}$embryos completely lack medial facial structures and exhibit a marked holoprosencephaly, phenotypes shared by Shh-null embryos (cf. Fig. 8H).

Molecular analysis of Shh, FoxA2, Nkx2.2 and Olig2 expression also revealed a progressive decrease in the proportion of these cell types such that no cells expressing any of these markers are detected in $\mathrm{Gas1}^{-/-} ; \mathrm{CdO}^{-/-}$ embryos (Fig. 8I-FF). Strikingly, and distinct from $\mathrm{Gas1}^{-/-}$; $\mathrm{Shh}^{+/-}$and $\mathrm{Cdo}^{-/-}$; $\mathrm{Shh}^{+/-}$embryos, $\mathrm{Gas1}^{-/-}$; $\mathrm{Cdo}^{-/-}$embryos also display loss of Shh expression from the notochord (Fig. 8Y-EE). While these data are consistent with a Shh-independent loss of notochord integrity, it is also possible that severely reduced Shh signaling is responsible for this phenotype, since both $S h h^{-/}$embryos and Dispatched 1 (Disp1) mutants display defects in notochord maintenance (Chiang et al. 1996; Kawakami et al. 2002; Ma et al. 2002). To test this possibility, the notochord-specific marker carbonic anhydrase III (CAIII) (Lyons et al. 1991) was used to examine notochord integrity in Gas1; Cdo embryos at E9.5 (Fig. 8GG$\mathrm{MM}$ ). Importantly, the notochord is intact in $\mathrm{E} 9.5 \mathrm{Gas}^{-1-}$;
$\mathrm{CdO}^{-/-}$embryos, suggesting that notochord formation and maintenance is not affected in these mutants. In contrast, examination of CAIII expression in $\mathrm{Shh}^{-/-} \mathrm{mu}-$ tants at E9.5 indicates a degenerating notochord (Fig. $8 \mathrm{NN})$. Thus, although $\mathrm{Gas1}^{-/-}$; $\mathrm{CdO}^{-/-}$embryos display quite severe defects, they do not recapitulate a complete loss of Shh activity. This conclusion was confirmed by the examination of craniofacial and vertebral defects at E18.5 by skeletal analysis (Supplementary Fig. 4).

$\mathrm{Gas1}^{-1-}$; $\mathrm{Cdo}^{-/-}$embryos display significantly more severe craniofacial defects than $\mathrm{Gas1}^{-/}$; $\mathrm{Shh}^{+/}$mutants, with a marked loss of both mandibular and maxillary components (Supplementary Fig. 4M). Additionally, Gas1 $^{-1-}$; Cdo ${ }^{-/-}$embryos show fusion of cervical verterbrae (Supplementary Fig. 4N), similar to loss of the Hhspecific transcription factor Gli3 (Mo et al. 1997), though the specification of vertebral components is distinct from $\mathrm{Shh}^{-1-}$ embryos (Chiang et al. 1996). In Shh ${ }^{-/-}$embryos, all ventral vertebral components are absent, whereas only ventral medial components are absent from $\mathrm{Gas1}^{-/-} ; \mathrm{CdO}^{-/-}$compound mutants. Further, in the 
limb, despite extensive overlap in the expression of Gas1 and Cdo (Liu et al. 2002; Tenzen et al. 2006), there appears to be no cooperativity between Gas1 and Cdo with regard to promotion of Shh signaling (Supplementary Fig. 5); the $\mathrm{Gas}^{-/-}$limb phenotype is similar to compound $\mathrm{Gas1}^{-/-}$; $\mathrm{CdO}^{-/-}$mutants. Thus, while Gas1 and Cdo are likely to cooperate in promoting Shh signaling, there are tissue-specific differences in the relative roles of these factors in the Shh pathway.

\section{Discussion}

Gas1 is a novel positive component of the Shh signaling cascade

Following the initial identification of Gas1 as a Hh-binding protein, subsequent in vitro experiments examining the role of Gas1 in Shh signaling led to the conclusion that it functions as an antagonist of Shh signaling (C.S. Lee et al. 2001a; Cobourne et al. 2004). However, several lines of evidence presented in this study argue that Gas1 is a positive component of the Shh signaling cascade that acts to promote Shh signaling in a Shh dosage-dependent manner. First, analysis of Gas1 mouse mutants reveals several defects including craniofacial, limb, and axon guidance deficiencies that are reminiscent of reduced Shh signaling. Second, detailed examination of ventral neural tube patterning, a process that depends critically on graded Shh signaling, also uncovers deficiencies in both FP and vp3 progenitor cell specification in $\mathrm{Gas}^{-/-}$ embryos. Third, the craniofacial, limb, and neural tube defects seen in Gas1 mutants are all significantly exacerbated by reducing the Shh dosage. Finally, chick electroporation experiments directly establish that Gas1 is capable of promoting Shh signaling in a cell-autonomous manner; a result similar to that obtained by Martinelli and Fan (2007). Importantly, these results are consistent with previous reports examining Gas1 function in other tissues where removal of Gas1 also results in phenotypes suggestive of reduced Shh signaling (C.S. Lee et al. 2001b; Liu et al. 2001, 2002). Overall, these data argue strongly that Gas1 is a novel positive component of the Shh signaling cascade.

In contrast to the pronounced defects in Shh signaling, however, no obvious abnormalities in Ihh-dependent long bone growth are detected in Gas1 mutant embryos. This is somewhat surprising, given that Gas1 binds Ihh with similar affinity to Shh (C.S. Lee et al. 2001a), and that there seems to be significant overlap between Gas1 and Thh expression in developing bone (St-Jacques et al. 1999; K.K. Lee et al. 2001). It may be that, similar to loss of Shh, reducing the Ihh dosage on a Gas1 mutant background will be necessary to identify any Ihh-dependent defects associated with the loss of Gas1.

\section{Gas1 cooperates with Cdo to promote Shh signaling}

In addition to the identification of Gas1 as a positive component of Shh signaling, data presented here suggest that Gas 1 cooperates with Cdo, a structurally unrelated, cell surface Shh-binding protein, to promote Shh signaling. How this occurs at the cellular level remains to be determined. As both factors bind Shh, one attractive hypothesis is that Gas1 and Cdo may form a physical complex together through Shh binding, and that this complex promotes Shh signaling, possibly through ligand presentation to the Shh receptor Ptch1. Future biochemical analyses examining whether such a complex is assembled and if so, determining the nature of such a complex will be critical next steps in understanding mechanistically how these proteins function. Additionally, given the recent report that the ciliary localization of the Hh signaling molecule Smo is critical for its function (Hacker et al. 2005), an examination of the subcellular localizations of these proteins may yield significant insight into their function. Considering that Gas1 is a GPIanchored protein (Stebel et al. 2000), and that Cdo is a transmembrane protein (Kang et al. 1997), an intriguing possibility is that these proteins display distinct membrane localizations in the absence of Shh, but that following ligand binding these proteins redistribute in order to promote Shh signaling through Ptch1.

Surprisingly, despite the strong cooperation seen between Gas1 and Cdo in the promotion of Shh signaling during craniofacial and neural tube development, there appear to be no such cooperative interactions in the limb. This result is especially striking given the Shhspecific limb defects seen in both $\mathrm{Gas1}^{-/-}$and $\mathrm{Gas1}^{-{ }_{-}^{-}}$; $\mathrm{Shh}^{+/-}$embryos, and that Gas1 and Cdo are expressed in overlapping domains in the limb (Lee and Fan 2001; Tenzen et al. 2006). One explanation is that other molecules with similar expression patterns and activity, notably Boc, may compensate for the loss of Gas1 and Cdo in the limb. Alternatively, inherent differences may exist in the reception and interpretation of Shh signals during limb and ventral neural tube development that underlie the contrasting phenotypes. Recent data from the limb suggest that both the level and duration of Shh signal exposure are critical for proper digit specification (Ahn and Joyner 2004; Harfe et al. 2004). Importantly, in the developing limb bud, Shh-expressing descendants contribute to the majority of Shh-dependent digits, while in the neural tube only FP cells ever express Shh and all ventral neural progenitors are initially specified by a notochord-derived Shh signal. In this regard, patterning of the neural tube is clearly more reliant on a secreted Shh signal. Thus, if Gas 1 and Cdo function to regulate cellular responses to secreted Shh ligand, then the mild digit specification defects and severe ventral neural tube patterning phenotypes seen in Gas1; Cdo compound mutants are entirely consistent.

The data presented here, however, do suggest an important similarity between digit specification and ventral neural tube patterning that has not been fully appreciated previously: time. Comparison of Gas1 and Cdo expression patterns indicates that they overlap only briefly in the ventral neural tube and notochord during early stages of neural patterning, yet analysis of $\mathrm{Gas1}^{-/-}$; $\mathrm{Cdo}^{-/-}$double mutants demonstrates a complete loss of $\mathrm{FP}$, vp3, and pMN progenitors, three cell types that de- 
pend critically on Shh for proper specification. Additionally, examination of $\mathrm{pMN}\left(\mathrm{Olig}^{+}\right)$cell specification at different time points during neural tube patterning of Gas1 $^{-/-}$; Shh ${ }^{+/-}$embryos suggests that these cells depend on Shh signaling not only for initial specification signals, but also for maintenance or expansion of cell fates postinitial patterning. These data suggest strongly that time is a critical factor controlling Shh-dependent patterning of the ventral neural tube. Thus, there is a brief, but important temporal window during ventral neural tube patterning where coexpression of Gas1 and Cdo is required for proper transduction of the Shh signal. This temporal dependence contrasts with current models of ventral neural tube patterning, where the level of Shh exposure is of primary importance (Hooper and Scott 2005).

\section{A model for cell surface regulation of Shh signaling}

A critical aspect of Gas1 promotion of Shh signaling is that Gas1 expression is down-regulated as Shh signaling levels increase. The same is true for $C d o$ and Boc, which are also general negative targets of Shh (Tenzen et al. 2006). Importantly, these expression patterns are in direct contrast to the transcriptional up-regulation of the negative Shh signaling components Ptch1 and Hhip1, which sequester Shh ligand and block signaling (Jeong and McMahon 2005). A synthesis of these data suggests the following model: Cell surface molecules that promote Shh signaling are initially expressed on Shh-responsive cells, sensitizing cells to even low levels of Shh ligand; as the level of Shh signaling increases, there is a transcriptional down-regulation of these positive components, and a concomitant up-regulation in the expression of negative feedback components, thus providing multiple mechanisms to tightly control both the range and level of Shh signal that is necessary for proper neural cell specification.

Importantly, the transcriptional regulation of these components is not an all or nothing response; instead, it is dynamically modified within the target field. For example, while Gas1 expression is lost in the most ventral cell types as development proceeds, its expression is maintained in Shh-responsive cells more dorsally that require lower levels of Shh signal for proper specification. Here, continued expression of Gas1 is clearly critical for mediating a robust response to the normal levels of Shh ligand that regulate cell identities in this position. This is evident from the dramatic loss of progenitor cell numbers when Shh dosage is decreased on a Gas $1 \mathrm{mu}-$ tant background. Additionally, an examination of $B O C$ and $C d o$ expression demonstrates that although their transcripts are dorsally restricted during neural tube specification, Cdo expression is preserved within the FP and its activity there is required at a late stage for maintenance of FP integrity (Tenzen et al. 2006), suggesting an ongoing role for these Shh signaling components in maintaining Shh expression in midline cells even after the initial establishment of Shh signaling. Overall, these data suggest that patterning of the ventral neural tube depends critically on both the level and duration of Shh action, and that Gas1 and Cdo comprise two key components that cooperate to regulate both aspects of this vital developmental process.

\section{Materials and methods}

Mice

The Gas $1^{\text {LacZ }}$ allele (referred to here as Gas1) was generated by Dr. C.M. Fan's laboratory (Carnegie Institution of Washington, Baltimore, MD). For details of the allele, please see the accompanying paper by Martinelli and Fan (2007). Cdo (Cole and Krauss 2003), Ptch1 (Goodrich et al. 1997), Shh (St-Jacques et al. 1998), and Smo (Zhang et al. 2001) mutant mice have all been described previously. Cdo mice were maintained on a $129 / \mathrm{Sv}$; C57BL6/J background, while Gas1 and Shh mice were maintained predominantly on a C57BL6/J background. Noon of the day on which a vaginal plug was detected was considered E0.5.

\section{Chick electroporation}

Gas1 was cloned into the pCIG vector (Megason and McMahon 2002) to enable coexpression of Gas1 with GFP to visualize electroporated cells. Ptch $1^{\Delta l o o p 2}$ constructs have been described previously (Tenzen et al. 2006). Electroporations were performed essentially as described previously (Tenzen et al. 2006). Gas1-pCIG and pCIG were injected into the neural tubes of Hamburger-Hamilton $(\mathrm{HH})$ stage 10-12 chicken embryos at concentrations of $1.0 \mu \mathrm{g} / \mu \mathrm{L}$ in PBS with $50 \mathrm{ng} / \mu \mathrm{L}$ Fast Green. For coelectroporation experiments, either Gas1-pCIG and pCIR or Gas1-pCIG and $\mathrm{Ptch}^{\Delta l o o p 2}$-pCIR were injected at concentrations of $0.75 \mu \mathrm{g} / \mu \mathrm{L}$ for each construct. Approximately $48 \mathrm{~h}$ following electroporation, embryos were recovered and fixed in $4 \%$ paraformaldehyde for subsequent immunofluorescent analysis.

\section{In situ hybridization and immunofluorescence}

Whole-mount digoxigenin in situ hybridization was performed as described (Wilkinson 1992). For immunofluorescent analysis, specimen collection, processing, and staining were performed essentially as previously described (Wijgerde et al. 2002; Jeong and McMahon 2005). Briefly, embryos were collected, fixed for $90 \mathrm{~min}$ in cold $4 \%$ paraformaldehyde, washed overnight at $4{ }^{\circ} \mathrm{C}$ in PBS, cryoprotected overnight at $4^{\circ} \mathrm{C}$ in PBS containing $30 \%$ sucrose, and frozen in OCT (Tissue-Tek). Twelve-micron sections were then cut for subsequent immunofluorescent analysis. During immunostaining, the following antibodies were used: rabbit-anti- $\beta$-gal $(1: 10,000$, Cappel), mouse anti-FoxA2 (1:20, Developmental Studies Hybridoma Bank [DSHB]), mouse anti-Shh (1:20, DSHB), mouse anti-Nkx2.2 (1:20, DSHB), mouse anti-Pax6 (1:20, DSHB), mouse anti-Pax7 (1:20, DSHB), rabbit anti-Nkx6.1 (1:600, gift of J. Jensen), mouse anti-Math1 (1:20, DSHB), mouse anti-Nkx6.1 (1:20, DSHB), rabbit anti-Olig2 (1:5000, gift of H. Takebayashi), rabbit anti-Nkx2.2 (1:4000, gift of T. Jessell), mouse anti-Isl1/2 (1:20, DSHB), rabbit anti-DsRed (1:700, Clontech). Nuclei were visualized with DAPI (1:30,000, Molecular Probes). Alexa 488, 568, and 633 secondary antibodies (1:500, Molecular Probes) were visualized on a Zeiss LSM510 confocal microscope. For quantitation of neural cell progenitors, at least two sections from three embryos of each genotype were counted. Statistical analyses were performed using a twotailed Student's $t$-test. 


\section{Skeletal analysis and whole-mount LacZ staining}

All skeletons were prepared according to a modified Alcian Blue/Alizarin Red staining protocol (Kessel et al. 1990; Wallin et al. 1994). Whole-mount detection of $\beta$-galactosidase activity was performed using X-gal (Shelton Scientific) as described previously (Whiting et al. 1991).

\section{Acknowledgments}

We are grateful to Dr. R. Krauss for the Cdo mutant and Dr. M. Scott for the Ptch1 mutant. We thank Drs. T. Jessell, H. Takebayashi, and J. Jensen for antibodies for neural tube analyses. FoxA2, Is11/2, Math1, Nkx2.2, Nkx6.1, Pax6, Pax7, and Shh antibodies were obtained from the Developmental Studies Hybridoma Bank developed under the auspices of the NICHD and maintained by The University of Iowa, Department of Biological Sciences, Iowa City, IA. We especially thank Chen-Ming Fan and David Martinelli for their generous sharing of the Gas1LacZ mouse strain and of key data prepublication. Work in A.P.M.'s laboratory was supported by a grant from the NIH (R37 NS033642). B.L.A. was supported by post-doctoral fellowship \#PF0512501DDC from the American Cancer Society.

\section{References}

Ahn, S. and Joyner, A.L. 2004. Dynamic changes in the response of cells to positive hedgehog signaling during mouse limb patterning. Cell 118: 505-516.

Ashe, H.L. and Briscoe, J. 2006. The interpretation of morphogen gradients. Development 133: 385-394.

Bottcher, R.T. and Niehrs, C. 2005. Fibroblast growth factor signaling during early vertebrate development. Endocr. Rev. 26: 63-77.

Briscoe, J. and Ericson, J. 2001. Specification of neuronal fates in the ventral neural tube. Curr. Opin. Neurobiol. 11: 43-49.

Briscoe, J., Pierani, A., Jessell, T.M., and Ericson, J. 2000. A homeodomain protein code specifies progenitor cell identity and neuronal fate in the ventral neural tube. Cell 101: 435445.

Briscoe, J., Chen, Y., Jessell, T.M., and Struhl, G. 2001. A hedgehog-insensitive form of patched provides evidence for direct long-range morphogen activity of sonic hedgehog in the neural tube. Mol. Cell 7: 1279-1291.

Callahan, C.A. and Thomas, J.B. 1994. Tau- $\beta$-galactosidase, an axon-targeted fusion protein. Proc. Natl. Acad. Sci. 91: 5972-5976.

Charron, F., Stein, E., Jeong, J., McMahon, A.P., and TessierLavigne, M. 2003. The morphogen sonic hedgehog is an axonal chemoattractant that collaborates with netrin-1 in midline axon guidance. Cell 113: 11-23.

Chen, Y. and Struhl, G. 1996. Dual roles for patched in sequestering and transducing Hedgehog. Cell 87: 553-563.

Chiang, C., Litingtung, Y., Lee, E., Young, K.E., Corden, J.L., Westphal, H., and Beachy, P.A. 1996. Cyclopia and defective axial patterning in mice lacking Sonic hedgehog gene function. Nature 383: 407-413.

Chiang, C., Litingtung, Y., Harris, M.P., Simandl, B.K., Li, Y., Beachy, P.A., and Fallon, J.F. 2001. Manifestation of the limb prepattern: Limb development in the absence of sonic hedgehog function. Dev. Biol. 236: 421-435.

Chuang, P.T. and McMahon, A.P. 1999. Vertebrate Hedgehog signalling modulated by induction of a Hedgehog-binding protein. Nature 397: 617-621.

Chuang, P.T., Kawcak, T., and McMahon, A.P. 2003. Feedback control of mammalian Hedgehog signaling by the Hedgehogbinding protein, Hip1, modulates Fgf signaling during branching morphogenesis of the lung. Genes \& Dev. 17: 342347.

Cobourne, M.T., Miletich, I., and Sharpe, P.T. 2004. Restriction of sonic hedgehog signalling during early tooth development. Development 131: 2875-2885.

Cole, F. and Krauss, R.S. 2003. Microform holoprosencephaly in mice that lack the Ig superfamily member Cdon. Curr. Biol. 13: 411-415.

Ding, Q., Motoyama, J., Gasca, S., Mo, R., Sasaki, H., Rossant, J., and Hui, C.C. 1998. Diminished Sonic hedgehog signaling and lack of floor plate differentiation in Gli2 mutant mice. Development 125: 2533-2543.

Echelard, Y., Epstein, D.J., St-Jacques, B., Shen, L., Mohler, J., McMahon, J.A., and McMahon, A.P. 1993. Sonic hedgehog, a member of a family of putative signaling molecules, is implicated in the regulation of CNS polarity. Cell 75: 14171430.

Epstein, D.J., McMahon, A.P., and Joyner, A.L. 1999. Regionalization of Sonic hedgehog transcription along the anteroposterior axis of the mouse central nervous system is regulated by Hnf3-dependent and -independent mechanisms. Development 126: 281-292.

Ericson, J., Rashbass, P., Schedl, A., Brenner-Morton, S., Kawakami, A., van Heyningen, V., Jessell, T.M., and Briscoe, J. 1997. Pax6 controls progenitor cell identity and neuronal fate in response to graded Shh signaling. Cell 90: 169-180.

Goodrich, L.V., Milenkovic, L., Higgins, K.M., and Scott, M.P. 1997. Altered neural cell fates and medulloblastoma in mouse patched mutants. Science 277: 1109-1113.

Hacker, U., Nybakken, K., and Perrimon, N. 2005. Heparan sulphate proteoglycans: The sweet side of development. Nat. Rev. Mol. Cell Biol. 6: 530-541.

Harfe, B.D., Scherz, P.J., Nissim, S., Tian, H., McMahon, A.P., and Tabin, C.J. 2004. Evidence for an expansion-based temporal Shh gradient in specifying vertebrate digit identities. Cell 118: 517-528.

Hooper, J.E. and Scott, M.P. 2005. Communicating with Hedgehogs. Nat. Rev. Mol. Cell Biol. 6: 306-317.

Ingham, P.W. and McMahon, A.P. 2001. Hedgehog signaling in animal development: Paradigms and principles. Genes \& Dev. 15: 3059-3087.

Jeong, Y. and Epstein, D.J. 2003. Distinct regulators of Shh transcription in the floor plate and notochord indicate separate origins for these tissues in the mouse node. Development 130: 3891-3902.

Jeong, J. and McMahon, A.P. 2005. Growth and pattern of the mammalian neural tube are governed by partially overlapping feedback activities of the hedgehog antagonists patched 1 and Hhip1. Development 132: 143-154.

Jeong, J., Mao, J., Tenzen, T., Kottmann, A.H., and McMahon, A.P. 2004. Hedgehog signaling in the neural crest cells regulates the patterning and growth of facial primordia. Genes \& Dev. 18: 937-951.

Jessell, T.M. 2000. Neuronal specification in the spinal cord: Inductive signals and transcriptional codes. Nat. Rev. Genet. 1: 20-29.

Kang, J.S., Gao, M., Feinleib, J.L., Cotter, P.D., Guadagno, S.N., and Krauss, R.S. 1997. CDO: An oncogene-, serum-, and anchorage-regulated member of the $\mathrm{Ig} /$ fibronectin type III repeat family. I. Cell Biol. 138: 203-213.

Kawakami, T., Kawcak, T., Li, Y.J., Zhang, W., Hu, Y., and Chuang, P.T. 2002. Mouse dispatched mutants fail to distribute hedgehog proteins and are defective in hedgehog signaling. Development 129: 5753-5765. 
Kessel, M., Balling, R., and Gruss, P. 1990. Variations of cervical vertebrae after expression of a Hox-1.1 transgene in mice. Cell 61: 301-308.

Lee, C.S. and Fan, C.M. 2001. Embryonic expression patterns of the mouse and chick Gas1 genes. Mech. Dev. 101: 293-297.

Lee, C.S., Buttitta, L., and Fan, C.M. 2001a. Evidence that the WNT-inducible growth arrest-specific gene 1 encodes an antagonist of sonic hedgehog signaling in the somite. Proc. Natl. Acad. Sci. 98: 11347-11352.

Lee, C.S., May, N.R., and Fan, C.M. 2001b. Transdifferentiation of the ventral retinal pigmented epithelium to neural retina in the growth arrest specific gene 1 mutant. Dev. Biol. 236: $17-29$.

Lee, K.K., Leung, A.K., Tang, M.K., Cai, D.Q., Schneider, C., Brancolini, C., and Chow, P.H. 2001. Functions of the growth arrest specific 1 gene in the development of the mouse embryo. Dev. Biol. 234: 188-203.

Lewis, P.M., Dunn, M.P., McMahon, J.A., Logan, M., Martin, J.F., St-Jacques, B., and McMahon, A.P. 2001. Cholesterol modification of sonic hedgehog is required for long-range signaling activity and effective modulation of signaling by Ptc1. Cell 105: 599-612.

Lewis, P.M., Gritli-Linde, A., Smeyne, R., Kottmann, A., and McMahon, A.P. 2004. Sonic hedgehog signaling is required for expansion of granule neuron precursors and patterning of the mouse cerebellum. Dev. Biol. 270: 393-410.

Liu, Y., May, N.R., and Fan, C.M. 2001. Growth arrest specific gene 1 is a positive growth regulator for the cerebellum. Dev. Biol. 236: 30-45.

Liu, Y., Liu, C., Yamada, Y., and Fan, C.M. 2002. Growth arrest specific gene 1 acts as a region-specific mediator of the Fgf10/Fgf8 regulatory loop in the limb. Development 129: 5289-5300.

Logan, C.Y. and Nusse, R. 2004. The Wnt signaling pathway in development and disease. Annu. Rev. Cell Dev. Biol. 20: 781-810.

Lyons, G.E., Buckingham, M.E., Tweedie, S., and Edwards, Y.H. 1991. Carbonic anhydrase III, an early mesodermal marker, is expressed in embryonic mouse skeletal muscle and notochord. Development 111: 233-244.

Ma, Y., Erkner, A., Gong, R., Yao, S., Taipale, J., Basler, K., and Beachy, P.A. 2002. Hedgehog-mediated patterning of the mammalian embryo requires transporter-like function of dispatched. Cell 111: 63-75.

Martinelli, D.C. and Fan, C.-M. 2007. Gas1 extends the range of Hedgehog action by facilitating its signaling. Genes \& Dev. (this issue) doi: 10.1101/gad.1546307.

Massague, J. 1998. TGF- $\beta$ signal transduction. Annu. Rev. Biochem. 67: 753-791.

Matise, M.P., Epstein, D.J., Park, H.L., Platt, K.A., and Joyner, A.L. 1998. Gli2 is required for induction of floor plate and adjacent cells, but not most ventral neurons in the mouse central nervous system. Development 125: 2759-2770.

McMahon, A.P., Ingham, P.W., and Tabin, C.J. 2003. Developmental roles and clinical significance of hedgehog signaling. Curr. Top. Dev. Biol. 53: 1-114.

Megason, S.G. and McMahon, A.P. 2002. A mitogen gradient of dorsal midline Wnts organizes growth in the CNS. Development 129: 2087-2098.

Milenkovic, L., Goodrich, L.V., Higgins, K.M., and Scott, M.P. 1999. Mouse patched 1 controls body size determination and limb patterning. Development 126: 4431-4440.

Miura, G.I. and Treisman, J.E. 2006. Lipid modification of secreted signaling proteins. Cell Cycle 5: 1184-1188.

Mo, R., Freer, A.M., Zinyk, D.L., Crackower, M.A., Michaud, J., Heng, H.H., Chik, K.W., Shi, X.M., Tsui, L.C., Cheng, S.H., et al. 1997. Specific and redundant functions of Gli2 and Gli3 zinc finger genes in skeletal patterning and development. Development 124: 113-123.

Okada, A., Charron, F., Morin, S., Shin, D.S., Wong, K., Fabre, P.J., Tessier-Lavigne, M., and McConnell, S.K. 2006. Boc is a receptor for sonic hedgehog in the guidance of commissural axons. Nature 444: 369-373.

Pabst, O., Herbrand, H., Takuma, N., and Arnold, H.H. 2000. NKX2 gene expression in neuroectoderm but not in mesendodermally derived structures depends on sonic hedgehog in mouse embryos. Dev. Genes Evol. 210: 47-50.

Roelink, H., Porter, J.A., Chiang, C., Tanabe, Y., Chang, D.T., Beachy, P.A., and Jessell, T.M. 1995. Floor plate and motor neuron induction by different concentrations of the aminoterminal cleavage product of sonic hedgehog autoproteolysis. Cell 81: 445-455.

St-Jacques, B., Dassule, H.R., Karavanova, I., Botchkarev, V.A., Li, J., Danielian, P.S., McMahon, J.A., Lewis, P.M., Paus, R., and McMahon, A.P. 1998. Sonic hedgehog signaling is essential for hair development. Curr. Biol. 8: 1058-1068.

St-Jacques, B., Hammerschmidt, M., and McMahon, A.P. 1999. Indian hedgehog signaling regulates proliferation and differentiation of chondrocytes and is essential for bone formation. Genes \& Dev. 13: 2072-2086.

Stebel, M., Vatta, P., Ruaro, M.E., Del Sal, G., Parton, R.G., and Schneider, C. 2000. The growth suppressing gas1 product is a GPI-linked protein. FEBS Lett. 481: 152-158.

Tenzen, T., Allen, B.L., Cole, F., Kang, J.S., Krauss, R.S., and McMahon, A.P. 2006. The cell surface membrane proteins Cdo and Boc are components and targets of the Hedgehog signaling pathway and feedback network in mice. Dev. Cell 10: $647-656$

Wallin, J., Wilting, J., Koseki, H., Fritsch, R., Christ, B., and Balling, R. 1994. The role of Pax-1 in axial skeleton development. Development 120: 1109-1121.

Wang, Y.P., Dakubo, G., Howley, P., Campsall, K.D., Mazarolle, C.J., Shiga, S.A., Lewis, P.M., McMahon, A.P., and Wallace, V.A. 2002. Development of normal retinal organization depends on Sonic hedgehog signaling from ganglion cells. Nat. Neurosci. 5: 831-832.

Whiting, J., Marshall, H., Cook, M., Krumlauf, R., Rigby, P.W., Stott, D., and Allemann, R.K. 1991. Multiple spatially specific enhancers are required to reconstruct the pattern of Hox-2.6 gene expression. Genes \& Dev. 5: 2048-2059.

Wijgerde, M., McMahon, J.A., Rule, M., and McMahon, A.P. 2002. A direct requirement for Hedgehog signaling for normal specification of all ventral progenitor domains in the presumptive mammalian spinal cord. Genes \& Dev. 16: $2849-2864$

Wilkinson, D.G. 1992. In situ hybridization: A practical approach. IRL Press at Oxford University Press, Oxford, New York.

Yao, S., Lum, L., and Beachy, P. 2006. The ihog cell-surface proteins bind Hedgehog and mediate pathway activation. Cell 125: 343-357.

Zhang, X.M., Ramalho-Santos, M., and McMahon, A.P. 2001. Smoothened mutants reveal redundant roles for Shh and Ihh signaling including regulation of $\mathrm{L} / \mathrm{R}$ symmetry by the mouse node. Cell 106: 781-792.

Zhang, W., Kang, J.S., Cole, F., Yi, M.J., and Krauss, R.S. 2006. Cdo functions at multiple points in the Sonic Hedgehog pathway, and Cdo-deficient mice accurately model human holoprosencephaly. Dev. Cell 10: 657-665. 


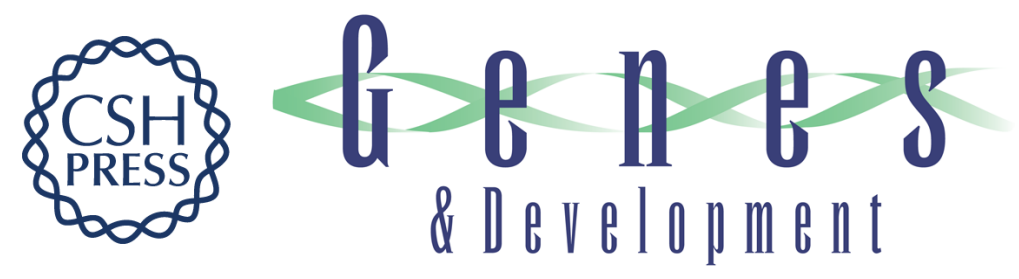

\title{
The Hedgehog-binding proteins Gas1 and Cdo cooperate to positively regulate Shh signaling during mouse development
}

\author{
Benjamin L. Allen, Toyoaki Tenzen and Andrew P. McMahon
}

Genes Dev. 2007, 21:

Access the most recent version at doi:10.1101/gad.1543607

\section{Supplemental http://genesdev.cshlp.org/content/suppl/2007/04/30/21.10.1244.DC1 Material}

References This article cites 64 articles, 23 of which can be accessed free at: http://genesdev.cshlp.org/content/21/10/1244.full.html\#ref-list-1

\section{License}

Email Alerting

Receive free email alerts when new articles cite this article - sign up in the box at the top Service

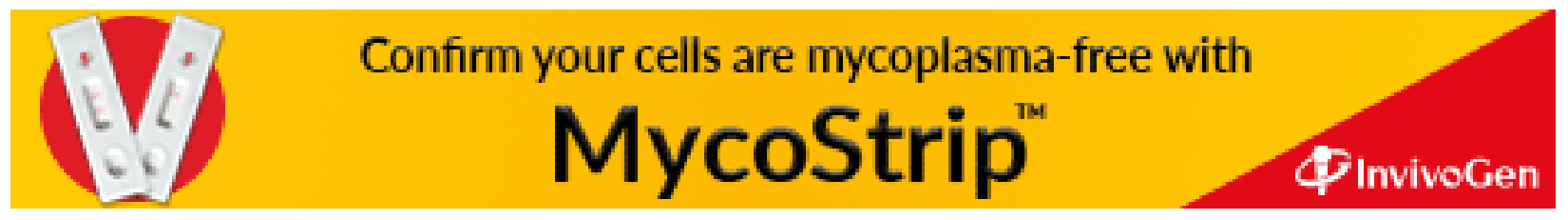

